\title{
正国pubvet
}

https://doi.org/10.31533/pubvet.v15n05a802.1-9

\section{Exigências nutricionais de cães filhotes: Revisão}

\author{
Ana Clara Silva Pinow ${ }^{1}$, , Josemara Silva Santos $^{2} \bullet$, Cristiane Lopes Mazzinghy ${ }^{2 *} \bullet$, \\ Mildre Loraine Pinto ${ }^{2} \theta$
}

${ }^{I}$ Graduanda em Medicina Veterinária do Centro Universitário Luterano de Palmas. Palmas - TO Brasil.

${ }^{2}$ Professora do Centro Universitário Luterano de Palmas, Departamento de Medicina Veterinária. Palmas - TO Brasil.

*Autor para correspondência, E-mail: cristiane.lopes@ceulp.edu.br

\begin{abstract}
Resumo. A nutrição possui grande importância para o crescimento e manutenção da saúde tanto humana como animal. As demandas nutricionais diárias dos animais são atendidas através de proteínas, carboidratos, lipídios e minerais, inseridos em dietas, com características específicas e variações conforme sua fase de vida para que haja desempenho corporal correto e manutenção diária. O objetivo do estudo consiste em realizar uma revisão sobre as principais exigências nutricionais de cães filhotes para acrescentar informações no âmbito da nutrição de pequenos animais.
\end{abstract}

Palavras-chave: Dietas, nutrientes, requerimentos

\section{Nutritional requirements of puppy dogs: Review}

\begin{abstract}
Nutrition has great importance for the growth and maintenance of both human and animal health. The daily nutritional demands of the animals are met through proteins, carbohydrates, lipids and minerals, inserted in diets, with specific characteristics and variations according to their stage of life so that there is correct body performance and daily maintenance. The aim of the study is to conduct a review of the main nutritional requirements of puppy dogs to add information in the context of small animal nutrition.
\end{abstract}

Keywords: Diets, nutrients, requirements

\section{Requisitos nutricionales de los cachorros: Revisión}

Resumen. La nutrición tiene gran importancia para el crecimiento y mantenimiento de la salud tanto humana como animal. Las demandas nutricionales diarias de los animales se satisfacen a través de proteínas, carbohidratos, lípidos y minerales, insertados en las dietas, con características específicas y variaciones según su etapa de vida para que exista un correcto funcionamiento corporal y mantenimiento diario. El objetivo del estudio es realizar una revisión de los principales requerimientos nutricionales de los cachorros para agregar información en el contexto de la nutrición de pequeños animales.

Palabras clave: Dietas, nutrientes, requerimientos

\section{Introdução}

A nutrição possui grande importância para o crescimento e manutenção da saúde tanto humana como animal. As demandas nutricionais diárias dos animais são atendidas através de proteínas, carboidratos, lipídios e minerais, inseridos em dietas, com características específicas e variações conforme sua fase de vida para que haja desempenho corporal correto e manutenção diária (Loureiro et al., 2017).

O Brasil ocupa o segundo lugar no ranking mundial em população de animais de estimação, com 55,1 milhões de cães em 2019. O país ocupa o quarto lugar em faturamento no setor pet, com um total 
de $\mathrm{R} \$ 22,3$ bilhões no ano de 2019. Estima-se, que entre 2018 e 2019 houve um crescimento de 8,8\% de faturamento, com destaque para o segmento de pet food, que correspondeu a 73,3\% do faturamento total do mercado brasileiro (ABINPET, 2019). Como consequência desse grande crescimento, há uma demanda elevada da população por opções de dietas sofisticadas, levando o mercado à oferta de diversidade de marcas com segmentos comerciais e nutricionais distintos. Isso se deve a relevante competitividade que se estabeleceu entre as fábricas de rações, fazendo com que haja no mercado alimentos diferenciados, com elevado valor nutricional e maior custo, e também alimentos econômicos, com menor valor, e menor valor nutricional (Carciofi, 2008).

De acordo com Carciofi (2008) a matéria-prima utilizada em dietas destinadas à alimentação animal adquiriram níveis de qualidade comparáveis aos de produtos designados ao consumo humano, devido à proximidade da relação entre o cão e o tutor. Com isso, as dietas dos cães modernos são formuladas com a inclusão de alimentos de origem vegetal e animal, para atenderem seus requerimentos nutricionais (Buff et al., 2014).

O objetivo dessa revisão de literatura refere-se em realizar as principais exigências nutricionais de cães filhotes, dispostas na literatura.

\section{Evolução alimentar do cão}

O cão doméstico está inserido na ordem dos carnívoros, em que seu desenvolvimento se refere ao princípio da era terciária (Parreira, 2007). Classifica-se como carnívoro não estrito, apesar de possuir sistema digestório reduzido e ceco não funcional, com ação digestiva dirigida para a digestão de proteínas e gorduras. Assim, os canídeos possuem dominância das enzimas proteinases e lipases, com inferior atividade amilolítica, devido ao tipo primitivo de sua alimentação, a caça, composta por carne e gordura, proporcionando fonte proteica e energética (Ahlstrøm \& Skrede, 1998; Simpson, 1998).

Em comparação aos outros animais, como ruminantes e herbívoros, que trituram totalmente seu alimento, os caninos ingerem o bolo alimentar com pouca ou inexistente mastigação, pois o seu trato gastrintestinal possibilita que esses animais devorem alimentos com abundância em períodos pouco frequentes. Os dentes estão adaptados para capturar e dilacerar a presa. Na boca ocorre a digestão que é restrita e o alimento é conduzido rapidamente para o estômago, sendo liberado para o intestino de forma intermitente. Os alimentos não absorvidos são transformados em fezes, em trinta e seis horas após a refeição (Case et al., 2011).

No período antes da domesticação, a dieta restringia-se a produtos de origem animal, como ratos, coelhos e aves, com dominância de proteína e lipídeos. O consumo de carboidratos era proveniente da ingestão do conteúdo do intestino das presas ou de vegetais crus. Entretanto, a proximidade com o homem, resultou em modificações significativas dos padrões de ingestão nesses animais (Case et al., 2011; Fraser et al., 1996).

O fácil acesso e a maior disponibilização dos alimentos diminuíram o gasto energético e aumentaram o consumo alimentar (Case et al., 2011; Fraser et al., 1996). Percebe-se que houve um elevado aporte de carboidratos com uma excelente modificação metabólica a sua nova dieta, razão pela qual o cão classificou-se como um carnívoro com hábitos alimentares onívoros (Jardim et al., 2019).

Há algumas décadas, os animais de companhia eram alimentados com os restos de refeições de seus proprietários e havia alguns fabricantes de rações no Brasil. A expansão desse segmento comercial, ocorreu devido ao aumento do poder aquisitivo dos proprietários pertencentes a grandes centros urbanos com consequente sofisticação dos padrões de consumo. Por outro lado, a transformação dos hábitos alimentares em benefício dos alimentos industriais está relacionada com a busca de alimentação saudável, equilibrada e principalmente praticidade (Carpim \& Oliveira, 2009).

\section{Exigências nutricionais de cães filhotes}

Em comparação às outras espécies animais, os caninos exibem superior variação no peso adulto frente às distintas raças existentes, desde miniaturas até raças gigantes. Essa variação resulta em adversidades para determinar a correta dieta de nutrientes, os quais possuem grandes oscilações, desde gastos em crescimento até manutenção basal ( 
Os filhotes possuem uma velocidade de crescimento elevada e variável, e por consequência são vulneráveis a condições de estresse que ocorrem durante o desenvolvimento. Entre essas condições, destacam-se a mudança da alimentação, produção de leite e estado de saúde da mãe, desmame, vacinações, erupção dentária e mudança de ambiente (NRC, 2006). Portanto, as rações em todas as fases da vida dos cães devem ser balanceadas e possuírem a finalidade de atender todas as exigências nutricionais, até que se tornem adultos. Nas suas formulações devem conter ingredientes de alta qualidade de modo proporcional, com proporções corretas de fontes de carboidrato, proteína, gordura e minerais, para favorecer, desse modo, o aproveitamento dos nutrientes pelos animais (NRC, 2006; Thompson, 2008).

A alimentação pode ser fornecida no formato úmido ou seco, ou ainda, ambos em conjunto. Observase que a mudança de dietas para rações de adultos, antes de os filhotes estarem totalmente desenvolvidos é uma das causas mais comuns de distúrbios nutricionais nesses animais, pois as rações contêm ingredientes em níveis diferentes. Alguns nutrientes são especialmente importantes durante o crescimento, e é essencial que o filhote receba o equilíbrio correto para que haja a nutrição adequada e por fim um excelente desenvolvimento (Grandjean \& Butterwick, 2012).

\section{Requerimento energético}

A energia é fundamental na vida dos animais e possui como função fornecer a força necessária para que as células tenham um bom funcionamento, e ainda é proveniente dos nutrientes, como gordura e carboidratos. Os lipídeos fornecem energia, ácidos graxos essenciais que não são sintetizados pelo organismo, servindo como carreadores para vitaminas lipossolúveis, e fornecendo sabor aos alimentos (NRC, 2006; Zoran, 2002). Além disso, formam a membrana celular e conferem proteção contra a perda de calor e também de órgãos contra choques mecânicos (Case et al., 2011).

De acordo com NRC (2006), a gordura é uma essencial fonte de energia que atua como provimento para o crescimento e refere-se à palatabilidade completa do alimento. Apresenta aproximadamente o dobro de calorias por grama quando comparada com a proteína ou o carboidrato, e por isso representa uma grande fonte de energia. Portanto, a necessidade diária dos filhotes é maior em relação os cães adultos, com o objetivo de atender suas necessidades energéticas durante essa importante fase de vida. As gorduras são constituídas por ácidos graxos, alguns considerados essenciais ao desenvolvimento saudável dos filhotes, como os ácidos graxos ômega-3 que são necessários ao desenvolvimento do cérebro e sistema nervoso, durante a gestação. Os ácidos graxos ômega-6 são fundamentais para o desenvolvimento e manutenção da pele e pelagem saudáveis. Apesar dos cães adultos sintetizarem quantidades suficientes de ácido araquidônico através do ácido linoleico através das rações, os filhotes são menos eficientes com relação a esse processo e também precisam de suprimentos na alimentação (NRC, 2006).

Os lipídeos de origem vegetal usadas nas rações para cães, são óleos de abacate, alecrim, linhaça (bruto ou cru), palma, girassol, soja (bruto ou cru), soja refinado e lecitina de soja. As gorduras de procedência animal são oriundas de aves, peixes, bovinos e suínos, apresentam-se como mais palatáveis e deixam os alimentos com aroma atrativo (França et al., 2011).

Os carboidratos são usados em rações como fontes de energia e fibra, sendo incorporados nas dietas em torno de $60 \%$, em diversas formas como, cereais, fécula de mandioca, milho (grão integral ou extrusado), amido de milho, arroz integral, quirera de arroz, sorgo, farelo de trigo e grão integral de cevada, entretanto, a principal é o amido (Case et al., 2011; Thompson, 2008). As fibras constituem-se uma forma complexas dos carboidratos que não são digeríveis pelo organismo animal (Dutcosky, 2011). A fibra bruta é essencial para manter a saúde intestinal, entretanto a inserção de farelos vegetais demasiadamente pode aumentar o seu nível e comprometer a digestão, absorção da matéria orgânica e energia nos caninos (Earle et al., 1998).

As fibras solúveis, como a pectina, promovem benefícios fisiológicos aos animais, incluindo aumento de volume e aspecto das fezes e diminuindo a possibilidade de diarreia, em razão do aumento na absorção de água. Além disso, proporcionam o desenvolvimento da mucosa intestinal, fornecendo energia à mucosa intestinal, diminuindo o $\mathrm{pH}$ do cólon, conferindo aumento da proteção contra infecções e diminuição da concentração de colesterol (Kritchevsky, 1997). 
As fibras insolúveis, como a celulose e lignina, são pouco fermentáveis e eliminadas na sua forma íntegra. São capazes de reter água e aumentam a massa fecal e o peso das fezes, sendo que, devido a sua consistência, estimulam o peristaltismo em função de sua ação agressiva sobre a musculatura intestinal (NRC, 2006).

Cães filhotes devem receber a quantidade correta de calorias devido ao seu rápido crescimento, aqueles com até oito meses de idade possuem exigências proteica e energética exacerbadas em comparação aos adultos. O nível de energia é aproximadamente $50 \%$ maior, e a proteína em dobro, sendo que para filhotes recomenda-se fornecer o mínimo de $25 \%$ da energia, a partir de uma proteína que apresente qualidade (Grandjean \& Butterwick, 2012; Lazzarotto, 2000).

Os requerimentos diários de energia que os filhotes necessitam possuem variações conforme a idade e raça. De acordo com Edney (1989), cães de raças pequenas exigem aproximadamente $200 \mathrm{kcal}$ por quilo de peso corporal até obter metade de seu desenvolvimento, a partir do qual inicia-se uma diminuição em tal exigência, em cerca de $150 \mathrm{kcal}$, que poderá ser reduzido gradativamente até alcançarem às exigências dos cães adultos. $\mathrm{O}$ mesmo autor afirma que existem ainda variações individuais quanto à exigência energética, pois alguns animais podem exigir uma variação de $20 \%$ abaixo ou acima do requerimento majoritário. Assim, é indispensável a supervisão clínica do estado físico do cão em crescimento, recebendo uma dieta equilibrada para atender as suas necessidades nutricionais.

\section{Requerimento proteico}

As proteínas fornecem aminoácidos, que são os elementos básicos para o crescimento do cão, pois este necessita assegurar o desenvolvimento de novos tecidos, especialmente o muscular, portanto é de alta significância a utilização desses elementos na dieta. Portanto, devem receber níveis corretos dos aminoácidos essenciais e também aporte eficaz de nitrogênio para a produção dos aminoácidos não essenciais (NRC, 2006). Os aminoácidos favorecem elevação da síntese de proteínas musculares e diminuição da sua degradação, redução do tempo de recuperação, aumento da resistência muscular, diminuição da fadiga muscular, conservação do glicogênio muscular e ainda, é fonte de energia na nutrição. Proteínas que possuem grande qualidade são aquelas que proporcionam quantidade apropriadas de todos os aminoácidos essenciais. A qualidade é proporcional à efetividade dos aminoácidos convertidos no tecido e, por sua vez, dependem da fonte de proteína, da concentração de aminoácidos essenciais e da sua biodisponibilidade (Thatcher et al., 2010).

Em alguns séculos passados, acreditava-se que a contração muscular prejudicava o conteúdo proteico dos músculos com o objetivo de proporcionar energia. Portanto, era fornecido alimentos com teores abundantes em proteínas para preservar a estrutura muscular e juntamente manter a energia corporal. Através de pesquisas, é conhecido que o tecido muscular não possui variação através da ingestão de dietas repletas de proteínas, mas a proteína ingerida pode ser transformada em componentes de outras moléculas e também induzir efeitos colaterais, principalmente uma sobrecarga para as funções hepática e renal, devido a eliminação da ureia (McArdle et al., 1998).

A quantidade de proteína adicionada na dieta dependerá da necessidade do animal, ou seja, existe um consumo maior de fontes proteicas nas fases de crescimento, gestação, lactação e para cães que exercem atividades físicas intensas Além disso, um suprimento insuficiente de proteína resultará em crescimento e desenvolvimento insatisfatórios (Grandjean, 2006; NRC, 2006). De acordo com Lazzarotto (2000), a quantidade de proteína na dieta para cães filhotes é de aproximadamente $25 \%$ da ingestão total de energia, contudo, esse nível terá variações conforme o valor biológico desse nutriente usado na composição da dieta.

As proteínas podem ser provenientes através de duas origens, animal e vegetal. De acordo com Brito et al. (2010), as fontes de origem animal mais empregadas são carne e subprodutos de frangos, bovinos, ovinos, caprinos, suínos e peixes, farinha de carne e osso, leite e ovos. E as de origem vegetal observadas, são soja em grão, cereais, farelos (gérmen de milho, soja, canola e amendoim), farinhas (trigo e arroz) e proteína texturizada de soja. 


\section{Requerimento mineral}

Os minerais são elementos inorgânicos e fundamentais para o crescimento normal. Estes constituem os tecidos dos animais em concentrações variáveis (Valadares Filho et al., 2016). Podem ser classificados como essenciais, os que formam as cinzas dos materiais biológicos após completa oxidação da matéria orgânica e representam de 5\% a $8 \%$ do total da MS (Grandjean, 2006; NRC, 2006). Além disso, classificam-se em macro minerais, tendo como representantes cálcio $(\mathrm{Ca})$, fósforo $(\mathrm{P})$, sódio $(\mathrm{Na})$, cloro $(\mathrm{Cl})$, potássio $(\mathrm{K})$, magnésio $(\mathrm{Mg})$ e enxofre $(\mathrm{S})$, cujas demandas são demonstradas em porcentagem, e em micro minerais ou elementos traço, simbolizados por cobalto $(\mathrm{Co})$, cobre $(\mathrm{Cu})$, iodo (I), ferro $(\mathrm{Fe})$, manganês $(\mathrm{Mn})$, molibdênio (Mo), selênio (Se), zinco $(\mathrm{Zn})$, cromo $(\mathrm{Cr})$ e flúor $(\mathrm{F})$, exigidos em pequena quantidade de miligramas por dia pelo animal (Valadares Filho et al., 2016).

Os cães filhotes necessitam de quantidades adequadas dos minerais, principalmente cálcio e fósforo, sendo fundamental para o seu eficaz desenvolvimento. No entanto, cuidados com os níveis desses elementos presentes na dieta são indispensáveis, pois possuem maiores exigências em comparação aos cães adultos, em razão de serem os elementos fundamentais para crescimento ósseo e formação do esqueleto (Lazzarotto, 2000).

Cálcio atua como mensageiro intracelular para transmissão de impulsos nervosos, contração muscular e constrição, relaxamento dos vasos sanguíneos, coagulação normal do sangue, ativação de diversas enzimas, secreção, fatores de liberação de hormônios e influencia na absorção de outros minerais, como Mn e no metabolismo do Zn (Andriguetto et al., 2003; Ogoshi et al., 2015).

O fósforo é um constituinte energético, tem participação na composição dos ácidos desoxirribonucleico (DNA) e ribonucleico (RNA), sistemas enzimáticos, parte dos dentes, membranas celulares, fosfolipídios e integridade da membrana celular (Valadares Filho et al., 2016). Este mineral possui atividade nos processos de utilização e transferência de energia, pois participa na produção de adenosina trifosfato (ATP) e adenosina difosfato (ADP), com isso há transporte de ácidos graxos, síntese de aminoácidos e proteínas. Nos fluidos celulares, existem aproximadamente $30 \%$ de $\mathrm{P}$ que auxiliam a manter a pressão osmótica, equilíbrio ácido-base, atividade dos neurônios e apetite (Suttle, 2010).

Segundo McGinnis (2014), os níveis mínimos adequados de Ca e P são respectivamente, 320 mg e $240 \mathrm{mg}$ por quilo de peso corporal por dia. O mesmo autor afirma que é importante preservar uma relação $\mathrm{Ca} / \mathrm{P}$ de 1,2-1, 4:1, respectivamente, para prevenir efeitos adversos à saúde geral, mas principalmente às estruturas ósseas. De acordo com Hazewinkel et al. (1991), cães de grande porte alimentados com $0,55 \%$ de $\mathrm{Ca}$, obtiveram fraturas ósseas e também em cães de pequeno porte que recebiam dietas contendo $0,05 \%$ de $\mathrm{Ca}$, comparado com aqueles que receberam nutrição com $0,33 \%$. Além disso, essa razão entre esses dois minerais é importante na determinação dos requisitos de vitamina D em filhotes de cães em crescimento (Grandjean \& Butterwick, 2012).

Sódio juntamente com o potássio mantém a pressão osmótica, o equilíbrio ácido-base e o controle do metabolismo da água no corpo e está associado à contração muscular e à função nervosa (Suttle, 2010). Além dessas funções, potássio possui ação no transporte de oxigênio e dióxido de carbono, fosforilação da creatina, atividade da piruvato quinase, captação celular de aminoácidos e síntese de proteínas, metabolismo de carboidratos, manutenção dos tecidos cardíaco e renal e atuação como cofator em muitas ativador ou cofator em muitas reações enzimáticas (Norman, 1982; Valadares Filho et al., $\underline{2016})$.

O cloro regula a pressão osmótica, o equilíbrio ácido-base e hídrico, e está presente na formação de ácido clorídrico no suco gástrico (González, 2000). O magnésio é indispensável para a respiração celular, transferência de fosfato entre ATP, ADP e adenosina monofosfato, condução nervosa normal, função muscular e formação mineral óssea. Atua também como catalizador de várias enzimas, promovendo a união de substrato e enzima, cofator imprescindível para enzimas bacterianas, como fosfohidrolases e fosfotransferases e síntese de vitamina B1 (Durand \& Komisarczuk, 1988; Ebel \& Günther, 1980).

O enxofre é um mineral responsável por compor proteínas, vitaminas e inúmeros hormônios. Já o cobalto é importante na eritropoiese e formação de ácido fólico e ainda compõe a vitamina B12 (González, 2000; Spinosa et al., 2006). E o iodo é imprescindível para a síntese da tiroxina (T3) e da 
triiodotironina (T4), que são importantes para o crescimento, desenvolvimento e à maturação físicomental. Sabe-se que a escassez desse micro mineral, ocasiona cretinismo em filhotes (Andriguetto et al., 2003; Beaver, 2001; Nelson \& Couto, 2015).

A função do cobre é integrar várias enzimas, como a citocromo oxidase, que possui finalidade de transportar elétrons durante a respiração aeróbica; lisil oxidase, que por sua vez, participa da formação do colágeno e elastina; a ceruloplasmina, enzima fundamental na absorção e transporte de ferro para a síntese de hemoglobina e a superóxido dismutase, que protege as células dos efeitos adversos no metabolismo do oxigênio. A deficiência desse elemento micro mineral, ocasiona falha na produção de colágeno e também na formação e pigmentação dos pelos, anemia, retardo no crescimento, ossos frágeis, diarreia, fibrose do miocárdio e ruptura da aorta (Andriguetto et al., 2003; López-Alonso, 2012).

Além de obter a função de produção de hemoglobinas, o ferro torna-se relevante para o transporte de oxigênio e dióxido de carbono, necessários à respiração celular, e faz parte das moléculas de mioglobina nos músculos e dos citocromos no fígado (Carvalho et al., 2006; Grotto, 2008). Os filhotes produzem quantidades elevadas de hemácias, portanto, sua exigência é maior em comparação aos caninos adultos (NRC, 2006). Entretanto, uma inadequada concentração deste mineral no organismo afeta diretamente a divisão celular, com formação de células eritrocitárias imaturas (Carvalho et al., 2006; Grotto, 2008), crescimento insatisfatório, letargia, fraqueza e diarreia (NRC, 2006).

O manganês é significativo ao desenvolvimento da matriz proteica dos ossos, funcionamento normal dos músculos, tecido nervoso, metabolização de sódio e potássio, à fosforilação oxidativa na mitocôndria, síntese de ácidos graxos e está associado no metabolismo dos aminoácidos e em muitas reações enzimáticas, principalmente as que estão ligadas ao metabolismo de energia (Andriguetto et al., 2003; Case et al., 2011). O molibdênio caracteriza-se como componente de enzimas (González, 2000).

As funções do selênio relacionam-se a defesa imune, pois é o componente vital da enzima glutationa peroxidase, esta por sua vez, é importante para à proteção das células e tecidos, e também da enzima iodotironina deiodinase tipo I, responsável pela conversão de T4 em T3 (Sordillo et al., 1997; Sordillo, 2013). Associado a vitamina E, realiza proteção antioxidante das membranas plasmáticas contra a ação dos peróxidos lipídicos (Gonzalez \& Silva, 2006).

O zinco atua na síntese e degradação dos carboidratos, lipídeos e proteínas, crescimento e desenvolvimento, função neurossensorial, funcionamento adequado do sistema imunológico, defesa antioxidante, transporte de dióxido de carbono, estabilidade da membrana dos eritrócitos, produção, armazenamento e secreção de insulina, testosterona e cortisol, e também, na transcrição e na tradução de polinucleotídios (González, 2000; Salgueiro et al., 2000; Suttle, 2010). Tecidos que apresentam acelerado crescimento, a deficiência desse micro mineral reduz a síntese de DNA e RNA, ocasionando impedimento na divisão e crescimento celular (López-Alonso, 2012). Nos caninos, existem relatos de dermatose reativa ao zinco (Ettinger et al., 2017).

O cromo atua como constituinte integral do fator de tolerância à glicose, que por sua vez, potencializa a atividade da insulina. Ambos, facilitam a relação entre a insulina e os receptores dos tecidos musculares e gordurosos (Mertz, 2012). A insuficiência desse mineral, interfere na ação da insulina e há modificação na degradação dos carboidratos, lipídeos e aminoácidos (Burton, 1995).

A ração é um alimento completo, não sendo necessário adicionar na dieta suplementos minerais, pois o excesso desses nutrientes pode afetar a digestibilidade do alimento e até produzir efeito adversos. Contudo, se houver requerimento ou carência, esses elementos devem ser fornecidos pela dieta e administrados sob a forma de sais purificados, como sulfato de ferro e cobre, óxido de zinco e magnésio, selenito de sódio e iodato de cálcio, com variações de gramas por dia, no caso dos macro minerais e até miligramas por dia, para os micro minerais (Grandjean, 2006; Grandjean \& Butterwick, 2012).

\section{Conclusão}

Os cães em crescimento possuem exigências nutricionais específicas e divergentes em comparação aos adultos, por isso é de suma importância o conhecimento sobre os nutrientes essenciais e suas quantidades adequadas, a fim de fornecer dietas equilibradas e satisfatórias para o desenvolvimento 
correto desses animais, sem causar desequilíbrios no organismo animal e consequentemente prejudicar o crescimento saudável dos filhotes.

\section{Referências}

ABINPET. (2019). Caderno especial Abinpet-Associação Brasileira da Indústria de Produtos para Animais de Estimação. Agro Analysis, 35(1), 35-40.

Ahlstrøm, Ø., \& Skrede, A. (1998). Comparative nutrient digestibility in dogs, blue foxes, mink and rats. The Journal of Nutrition, 128(12), 2676S-2677S. https://doi.org/10.1093/jn/128.12.2676s.

Andriguetto, J. M., Perly L., Y., \& Minardi, I. (2003). Nutrição Animal (Vol. 66). Editora Nobel.

Beaver, B. V. (2001). Comportamento canino: um guia para veterinários. Roca.

Brito, C. B. M., Félix, A. P., Jesus, R. M., França, M. I., Oliveira, S. G., Krabbe, E. L., \& Maiorka, A. (2010). Digestibility and palatability of dog foods containing different moisture levels, and the inclusion of a mould inhibitor. Animal Feed Science and Technology, 159(3-4), 150-155. https://doi.org/10.1016/j.anifeedsci.2010.06.001.

Buff, P. R., Carter, R. A., Bauer, J. E., \& Kersey, J. H. (2014). Natural pet food: A review of natural diets and their impact on canine and feline physiology. Journal of Animal Science, 92(9), 3781-3791. https://doi.org/10.2527/jas.2014-7789.

Burton, J. L. (1995). Supplemental chromium: its benefits to the bovine immune system. Animal Feed Science and Technology, 53(2), 117-133. https://doi.org/10.1016/0377-8401(95)02016-S.

Carciofi, A. C. (2008). Fontes de proteína e carboidratos para cães e gatos. Revista Brasileira de Zootecnia, 37(SPE), 28-41. https://doi.org/10.1590/S1516-35982008001300005.

Carpim, W. G., \& Oliveira, M. C. (2009). Qualidade nutricional de rações secas para cães adultos comercializadas em Rio Verde-GO. Biotemas, 22(2), 181-186. https://doi.org/10.5007/21757925.2009v22n2p181.

Carvalho, M. C., Baracat, E. C. E., \& Sgarbieri, V. C. (2006). Anemia ferropriva e anemia de doença crônica: distúrbios do metabolismo de ferro. Segurança Alimentar e Nutricional, 13(2), 54-63. https://doi.org/10.20396/san.v13i2.1832.

Case, L. P., Daristotle, L., Hayek, M. G., \& Raasch, M. F. (2011). Canine and feline nutrition. Elsevier.

Durand, M., \& Komisarczuk, S. (1988). Influence of major minerals on rumen microbiota. The Journal of Nutrition, 118(2), 249-260.

Dutcosky, S. (2011). Análise sensorial de alimentos (Vol. 1). 3th ed. Editora Champagnat, Curitiba, Paraná.

Earle, K. E., Kienzle, E., Opitz, B., Smith, P. M., \& Maskell, I. E. (1998). Fiber affects digestibility of organic matter and energy in pet foods. The Journal of Nutrition, 128(12), 2798S-2800S.

Ebel, H., \& Günther, T. (1980). Magnesium metabolism: a review. 18, 257-270.

Edney, A. T. B. (1989). El libro Waltham de nutrición de perros y gatos: manual para veterinarios y estudiantes (Issue Sirsi) i9788420006543). Acribia.

Ettinger, S. J., Feldman, E. C., \& Cote, E. (2017). Textbook of Veterinary Internal Medicine-eBook. Elsevier Health Sciences.

França, J., Saad, F., Saad, C. E. P., Silva, R. C., \& Reis, J. S. (2011). Avaliação de ingredientes convencionais e alternativos em rações de cães e gatos. Revista Brasileira de Zootecnia, 40, 222 231.

Fraser, C. M., Bergeron, J. A., Mays, A., \& Aiello, S. A. (1996). Manual Merck de Veterinária: um manual de diagnóstico, tratamento, prevenção e controle de doenças para o veterinário. Roca.

González, F. H. D. (2000). Uso do perfil metabólico para determinar o status nutricional em gado de corte. In F. H. D. Gonzáles, J. O. J. Barcellos, \& L. A. O. Ribeiro (Eds.), Perfil metabólico em ruminantes: seu uso em nutrição e doenças nutricionais. Universidade Federal do Rio Grande do Sul, Faculdade de Veterinária.

Gonzalez, F. H. D., \& Silva, S. C. (2006). Introdução à bioquímica clínica animal. Gráfica de Universidade Federal do Rio Grande do Sul. 
Grandjean, D. (2006). Tudo o que você precisa saber sobre o papel dos nutrientes na saúde de cães e gatos. Intergraf.

Grandjean, D., \& Butterwick, R. (2012). Waltham: Pocket book of essential nutrition for cats and dogs. Beyond Design Solutions Ltda.

Grotto, H. Z. W. (2008). Iron metabolism: An overview on The main mechanisms involved in its homeostasis. Revista Brasileira de Hematologia e Hemoterapia, 30, 390-397. https://doi.org/10.1590/S1516-84842008000500012.

Hazewinkel, H. A. W., Van Den Brom, W. E., Van'T Klooster, A. T., Voorhout, G., \& Van Wees, A. (1991). Calcium metabolism in Great Dane dogs fed diets with various calcium and phosphorus levels. The Journal of Nutrition, 121(suppl_11), S99-S106. https://doi.org/10.1093/jn/121.suppl_11.s99 .

Jardim, A. M., Camargo, E., Rossi, H., Pereira, I., Trettene, L., Machado, P. P., Nandi, R. S., Garbelini, V. H., \& Fabreti, A. K. (2019). Nutrição de pequenos animais: Alternativas na alimentação de cães e gatos.

Kritchevsky, D. (1997). Cereal fiber and lipidemia. Cereal Foods World, 42(2), 80-85.

Lazzarotto, J. J. (2000). Nutrição e alimentação de filhotes de cães. Revista Da FZVA, 7(1), 157-162.

López-Alonso, M. (2012). Trace minerals and livestock: not too much not too little. International Scholarly Research Notices, 2012, 1-18. https://doi.org/10.5402/2012/704825.

Loureiro, K. C., Haese, D., Kill, J. L., Pires, A. F., Fernandes, D. R., Colnago, G. L., Lucas, W. H., \& Gama, G. O. (2017). Ingredients derived from the slaughter of bovines in dog food. Ciência Rural, 47(6), 1-6. https://doi.org/10.1590/0103-8478cr20150778.

McArdle, W. D., Katch, F. I., \& Katch, V. L. (1998). Fisiologia do exercício: Energia, nutrição e desempenho humano RJ: Ed. Guanabara Koogan.

McGinnis, T. (2014). The well dog book: The classic comprehensive handbook of dog care. Random House.

Mertz, W. (2012). Trace elements in human and animal nutrition (Vol. 2). Academic Press, Inc.

Nelson, R. W., \& Couto, C. G. (2015). Medicina interna de pequenos animais (Issue 1). Elsevier Editora.

Norman, J. (1982). How to understand acid-base. A quantitative acid-base primer for biology and medicine. British Journal of Anaesthesia, 54(3), 368. https://doi.org/10.1093/bja/54.3.368.

NRC. (2006). Nutrient requirements of dogs and cats. The National Academies Press.

Ogoshi, R. C. S., Reis, J. S., Zangeronimo, M. G., \& Saad, F. M. O. B. (2015). Conceitos básicos sobre nutrição e alimentação de cães e gatos. Ciência Animal, 25(1), 64-75.

Parreira, P. R. (2007). Aspectos fundamentais da determinação da exigência energética de cães domésticos. Revista Acadêmica Ciência Animal, 5(4), 415-422.

Salgueiro, M. J., Zubillaga, M., Lysionek, A., Sarabia, M. I., Caro, R., De Paoli, T., Hager, A., Weill, R., \& Boccio, J. (2000). Zinc as an essential micronutrient: a review. Nutrition Research, 20(5), 737 755. https://doi.org/10.17221/2010-VETMED.

Simpson, J. W. (1998). Diet and large intestinal disease in dogs and cats. The Journal of Nutrition, 128(12), 2717S-2722S. https://doi.org/10.1093/jn/128.12.2717s.

Sordillo, L M, Shafer-Weaver, K., \& Rosa, D. (1997). Immunobiology of the mammary gland. Journal of Dairy Science, 80(8), 1851-1865. https://doi.org/10.3168/jds.S0022-0302(97)76121-6.

Sordillo, Lorraine M. (2013). Selenium-dependent regulation of oxidative stress and immunity in periparturient dairy cattle. Veterinary Medicine International, 2013, 1-8. https://doi.org/http://dx.doi.org/10.1155/2013/154045.

Spinosa, H. S. de S., Górniak, S. L., \& Bernardi, M. M. (2006). Farmacologia aplicada à medicina veterinária. Koogan Guanabara.

Suttle, N. F. (2010). The mineral nutrition of livestock. CABI Publishing.

Thatcher, C., Hand, M. S., \& Remillard, R. (2010). Small animal clinical nutrition: an iterative process. Small Animal Clinical Nutrition, 3-21. 
Thompson, A. (2008). Ingredients: where pet food starts. Topics in Companion Animal Medicine, 23(3), 127-132. https://doi.org/10.1053/j.tcam.2008.04.004.

Valadares Filho, S. C., Costa e Silva, L. F., Gionbelli, M. P., Rotta, P. P., Marcondes, M. I., Chizzotti, M. L., \& Prados, L. F. (2016). Exigências nutricionais de zebuínos puros e cruzado-BR-Corte (Vol. 1). Universidade Federal de Viçosa. https://doi.org/10.5935/978-85-8179-111-1.2016b001.

Zoran, D. L. (2002). The carnivore connection to nutrition in cats. Journal of the American Veterinary Medical Association, 221(11), 1559-1567. https://doi.org/10.2460/javma.2002.221.1559.

Histórico do artigo:

Recebido: 12 de agosto de 2020 . Aprovado: 19 de setembro de 2020.

Disponível online: 7 de janeiro de 2021.
Licenciamento: Este artigo é publicado na modalidade Acesso Aberto sob a licença Creative Commons Atribuição 4.0 (CC-BY 4.0), a qual permite uso irrestrito, distribuição, reprodução em qualquer meio, desde que o autor e a fonte sejam devidamente creditados. 